\title{
A Strengths Approach to Research
}

University of Minnesota - Twin Cities

\section{"Increasing student engagement is everyone's work." - George Kuh}

\section{What are Strengths?}

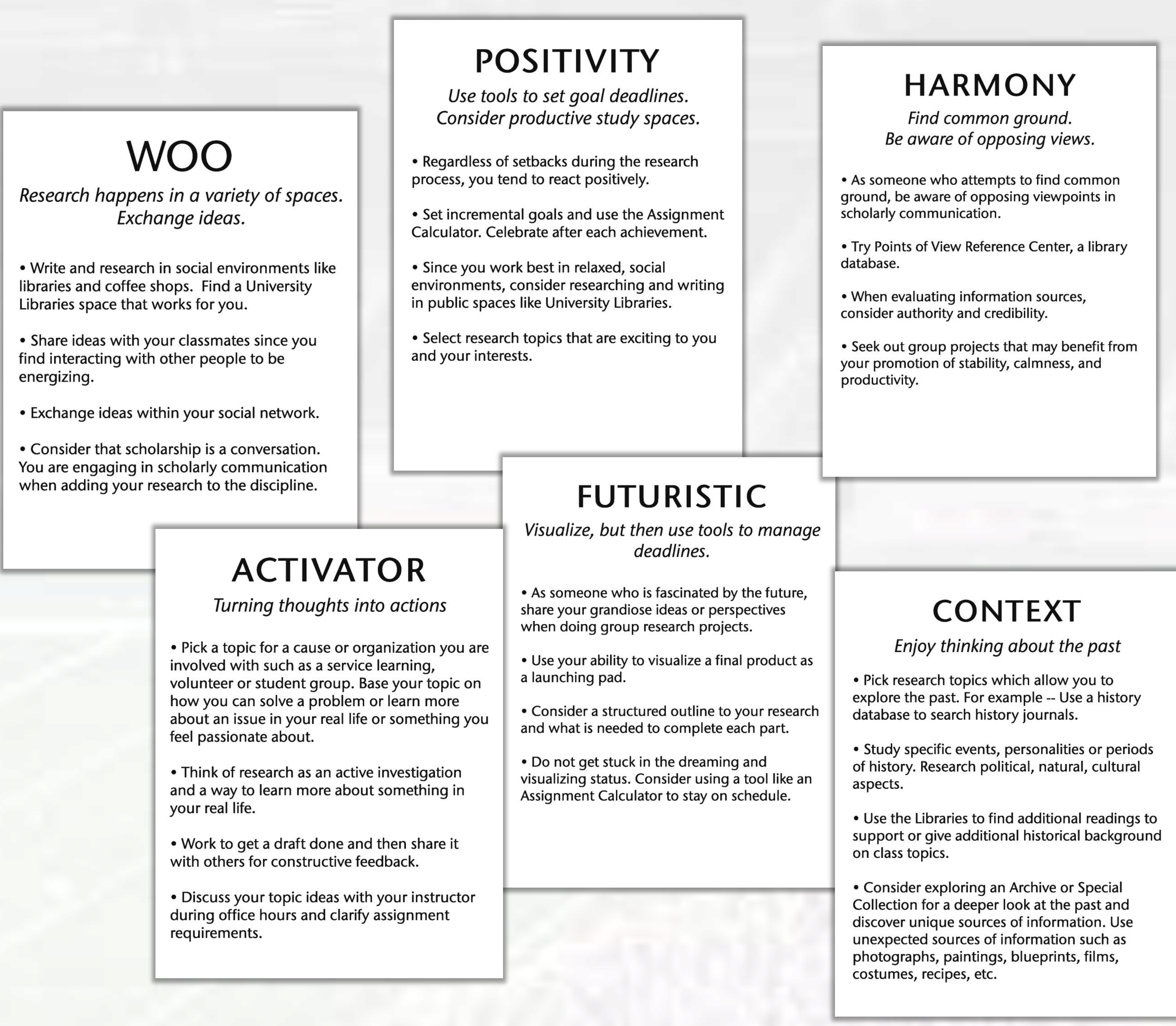

In 2009, the University of Minnesota began to give all 5000+ incoming students the StrengthsFinder assessment

(http://strengths.umn.edu/). Each student received their top 5 talents.

Student received training during Welcome Week, in workshops and in their interactions with Student Affairs staff, academic advisors and career services.

- Students learned to apply their Strengths in selecting a major, student employment, work on student groups, career goals and more. Connections in academics were fewer.

In 2014, the U Libraries developed a website and cards to connect each of the 34 talents or Strengths to tips on being more effective in doing research using the Libraries including our online tools and our spaces. We recommended specific Libraries' spaces (e.g. deep quiet) and databases (e.g. Points of View Reference) and tools (e.g. Assignment Calculator), etc.

\section{Contacts}

Amy Riegelman (aspringer@umn.edu), Librarian for Government Information, Psychology and Data Services

Kate Peterson (katep@umn.edu), Undergraduate Services Librarian

\section{What is Metacognition?}

Metacognitive strategies improve learning. Research on metacognition has shown that having an awareness of your strengths before you begin a task or project may help you to learn more effectively.

Specifically, there is a benefit to evaluating your strengths and weaknesses. There are benefits to planning an approach and then monitoring progress. According to research done by Schoenfeld, experts dedicate time to analyzing and planning an approach whereas students tend to read the content and then immediately begin exploring.
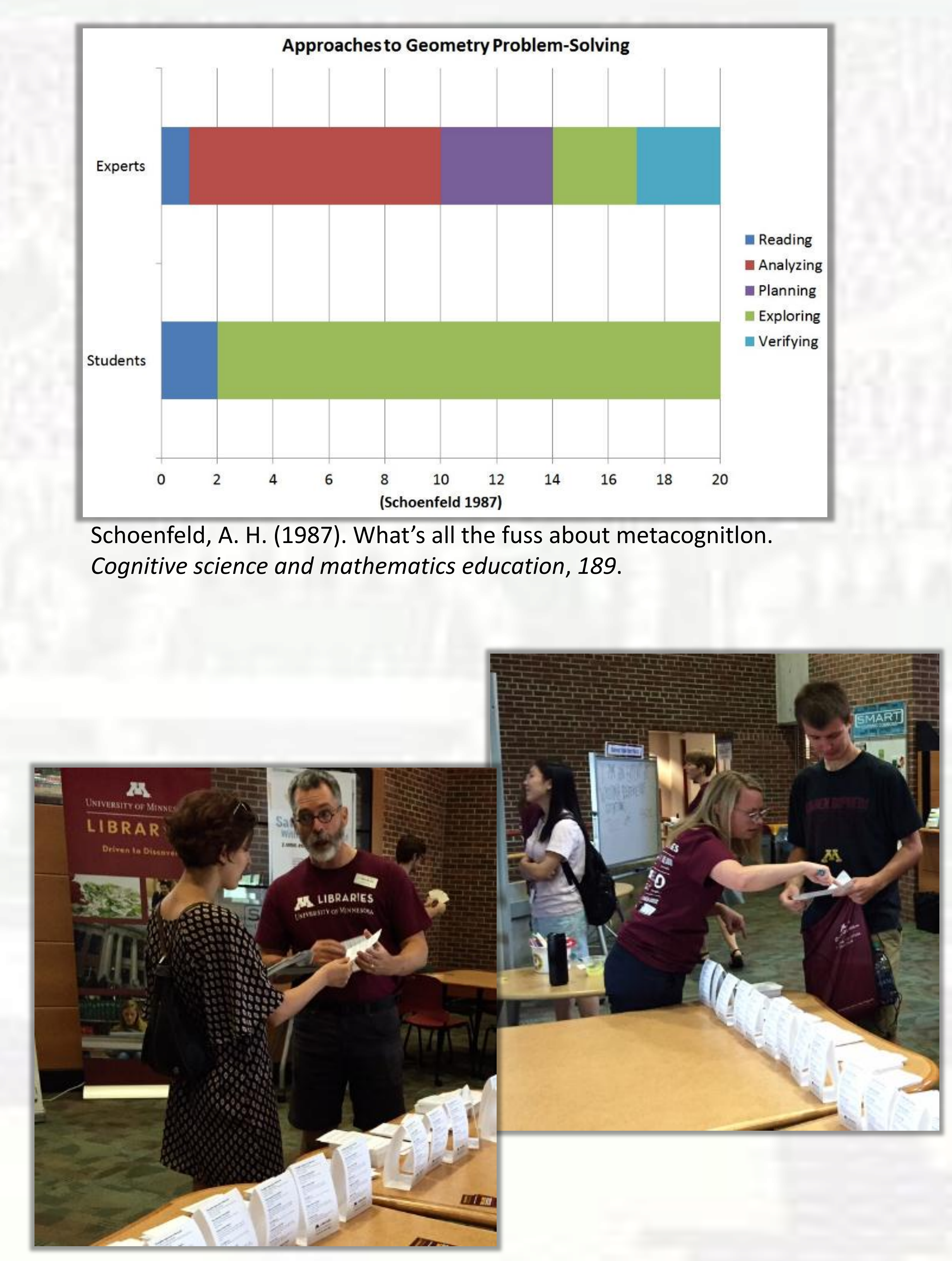

\section{Why connect Strengths + Metacognition + Libraries?}

1. We know from our own research that use of the Libraries and our online materials, during the first year, is correlated to increased GPA and increased retention.

2. We know that many students don't like research papers.

3. We need new ways to work with student services. We want to demonstrate that Libraries are focused on engagement.

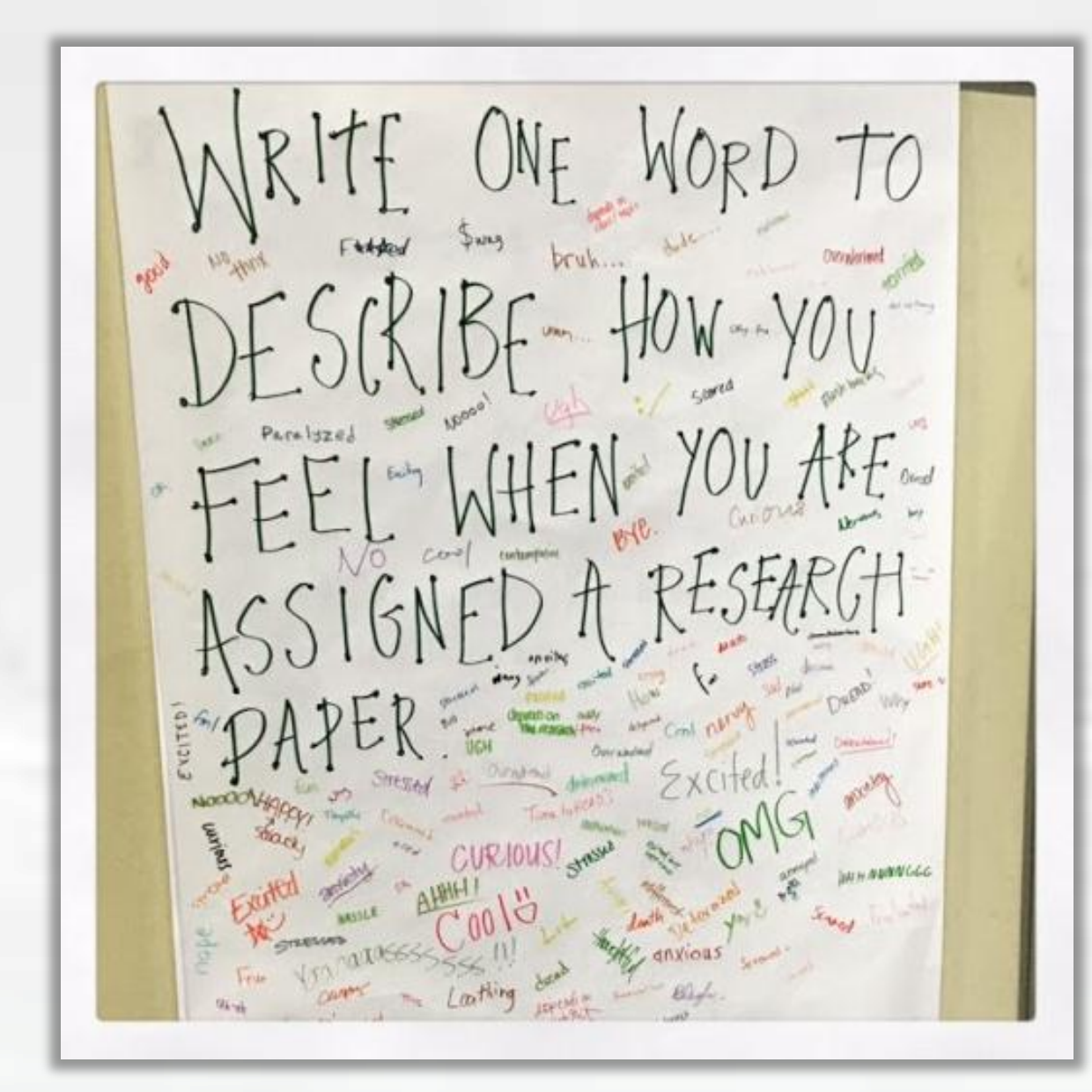

4. We have a lot to offer students in how they are choosing to get their academic work done from quiet study spaces to support for research to collaboration space, etc. We need to connect the type of work students need to do directly with our specific services and spaces-instead of relying on them to connect the dots.

5. We wanted to encourage students to be involved in their own learning - supporting metacognitive strategies.

\section{Early Impact}

- The information is now displayed on a library web page, www.lib.umn.edu/strengths. Cards with each Strength and unique library research tips were given out at an Orientation event that for 3500 students. We received positive feedback from both students and Orientation Leaders.

- We shared this work with over 40+ academic advisors from the College of Liberal Arts in late September and the concept of mapping the Strengths was very well received. The talked about how they could include this work in their own work with students.

\section{References}

